\title{
A prospective cohort study of the long-term effects of CPAP on carotid artery intima-media thickness in Obstructive sleep apnea syndrome
}

\author{
David S Hui ', Qing Shang, Fanny W Ko, Susanna S Ng, Cheuk-Chun Szeto, Jenny Ngai, Alvin H Tung, Kin-Wang To
} , Tat-On Chan and Cheuk-Man Yu

\begin{abstract}
Objective: To examine the long-term effect of CPAP on carotid artery intima-media thickness (IMT) in patients with Obstructive sleep apnea syndrome(OSAS).

Methods: A prospective observational study over 12 months at a teaching hospital on 50 patients newly diagnosed with OSAS who received CPAP or conservative treatment (CT). Carotid IMT was assessed with B-mode Doppler ultrasound from both carotid arteries using images of the far wall of the distal $10 \mathrm{~mm}$ of the common carotid arteries at baseline, 6 months and 12 months.
\end{abstract}

Measurements and results [mean (SE)]: Altogether 28 and 22 patients received CPAP and CT respectively without significant differences in age $48.8(1.8)$ vs $50.5(2.0) \mathrm{yrs}, \mathrm{BMl} 28.2(0.7)$ vs $28.0(1.2) \mathrm{kg} / \mathrm{m} 2$, ESS $13.1(0.7)$ vs 12.7 (0.6), AHI 38(3) vs 39(3)/hr, arousal index 29(2) vs 29(2)/hr, minimum $\mathrm{SaO}_{2} 75(2)$ vs $77(2) \%$ and existing comorbidities. CPAP usage was 4.6(0.3) and 4.7(0.4)hrs/night over 6 months and 1 year respectively. Carotid artery IMT at baseline, 6 months, and 12 months were 758(30), 721(20), and 705(20)micron for the CPAP group versus 760(30), 770(30), and 778(30)micron respectively for the CT group, $p=0.002$.

Among those free of cardiovascular disease $(n=24)$, the carotid artery IMT at baseline, 6 months and 12 months were 722(40), 691(40), and 659(30)micron for the CPAP group ( $n=12)$ with usage 4.5(0.7) and 4.7(0.7) hrs/night over 6 months and 12 months whereas the IMT data for the CT group $(n=12)$ were 660(20), 685(10), and 690(20) micron respectively, $\mathrm{p}=0.006$.

Conclusions: Reduction of carotid artery IMT occurred mostly in the first 6 months and was sustained at 12 months in patients with reasonable CPAP compliance.

\section{Background}

Obstructive sleep apnea syndrome (OSAS) is characterized by repetitive episodes of upper airway obstruction causing daytime sleepiness, impaired cognitive function and poor health status [1]. Untreated OSA is associated with increased risks of developing fatal and non-fatal cardiovascular events $[2,3]$. Three large prospective cohort studies have shown that untreated OSA is an independent risk factor for all-cause mortality after long-term follow-up [4-6]. Untreated OSA is also

\footnotetext{
* Correspondence: dschui@cuhk.edu.hk

SH Ho Sleep Apnea Management Center, Department of Medicine \&

Therapeutics, The Chinese University of Hong Kong, Prince of Wales Hospital, 30-32 Ngan Shing St., Shatin, New Territories, Hong Kong
}

associated with dysglycemia, systemic inflammation, endothelial dysfunction, platelet activation, and other cardiovascular consequences such as cardiac arrhythmias especially atrial fibrillation (AF), coronary artery disease, asymptomatic early atherosclerosis, and silent brain infarction [7].

In recent years, carotid artery IMT, measured by Bmode ultrasound, has been shown to be a highly reproducible test and correlate well with traditional vascular risk factors. It may predict the likelihood of acute coronary events and stroke in asymptomatic healthy subjects $[8,9]$. Several studies have shown that the severity of OSA is independently related to the carotid artery IMT, with the severity of OSA-related hypoxemia more

C Biomed Central

(c) 2012 Hui et al; licensee BioMed Central Ltd. This is an Open Access article distributed under the terms of the Creative Commons Attribution License (http://creativecommons.org/licenses/by/2.0), which permits unrestricted use, distribution, and reproduction in any medium, provided the original work is properly cited. 
important than the frequency of obstructive events $[10,11]$. One randomized controlled trial (RCT) has shown that continuous positive airway pressure (CPAP) $(\mathrm{n}=12)$ over 4 months could reduce carotid artery IMT in patients with severe OSAS free of existing cardiovascular diseases versus controls $(n=12)$ [12], but another recent RCT of 3 months treatment duration has failed to show any significant change in carotid artery IMT when comparing CPAP $(n=43)$ versus sham CPAP (n =43) [13]. Hence it remains unknown whether CPAP can consistently reduce the carotid artery IMT in patients with OSAS or to a greater magnitude over a longer treatment period. This study examined the longterm effects of CPAP versus conservative treatment (CT) on carotid artery IMT over a period of 1 year.

\section{Methods}

We conducted a prospective observational study of the treatment effects on carotid artery IMT in patients newly diagnosed with OSAS. OSAS, as defined by an overnight polysomnography (PSG) showing apneahypopnea index (AHI) $\geq 5$ /hour of sleep plus excessive daytime sleepiness or two of the following symptoms: choking or gasping during sleep, recurrent awakenings from sleep, unrefreshed sleep, daytime fatigue, and impaired concentration $[14,15]$. The patients were recruited from the Respiratory Clinic, Prince of Wales Hospital, Hong Kong. The inclusion criteria of the study included age 20 to $80 \mathrm{yrs}$, and AHI $\geq 5 \mathrm{hr}$ on PSG with symptoms of OSA as described above. The exclusion criteria included patients having problems staying awake during driving, professional drivers, shift work, recent myocardial infarction, unstable angina, underlying malignancy, and treatment of hyperlipidemia with statins or other lipid-lowering agents. Our study was approved by the Ethics Committee of the Chinese University of Hong Kong (CRE-2005.135) and appropriate informed written consent was obtained from the subjects.

\section{Sleep assessment}

Overnight diagnostic PSG (Healthdyne Alice 4, USA) was performed for every subject recording electroencephalogram(EEG), electro-oculogram, submental electromyogram (EMG), bilateral anterior tibial EMG, electrocardiogram, chest and abdominal wall movement by inductance plethysmography, airflow measured by a nasal pressure transducer [PTAF2, Pro-Tech, Woodinville, WA, USA] and supplemented by an oral thermister, and finger pulse oximetry as described in our previous studies $[15,16]$. Sleep stages were scored according to standard criteria by Rechtshaffen and Kales [17]. Apnea was defined as cessation of airflow for $>10$ seconds and hypopnea as a reduction of airflow of $\geq$
$50 \%$ for $>10$ seconds plus an oxygen desaturation of $>$ $3 \%$ or an arousal. An arousal was scored if there was a 3 sec or longer abrupt shift in EEG frequency to alpha or theta or $>16 \mathrm{~Hz}$, following at least $10 \mathrm{sec}$ of sleep, and if arising in REM there must be a rise in EMG tone [18].

Following confirmation of OSA, all patients were arranged to undergo an attended overnight autoCPAP titration on the second night of the sleep study. All patients were given a basic CPAP education program by our respiratory nurse supplemented by education brochure $[15,16]$. The nurse would fit a comfortable CPAP mask from a wide range of selection for every patient, who was then given a short trial of CPAP therapy with the Autoset (ResMed, Sydney, Australia) CPAP device for approximately 30 minutes for acclimatization in the afternoon. Following the overnight autoCPAP titration study, each patient was interviewed by the physician on duty and invited to participate in the serial carotid IMT study.

\section{Group 1 (CT)}

After confirmation of significant OSAS and completion of overnight attended autoCPAP titration, patients who were not keen to start CPAP yet were encouraged to a) avoid sleep deprivation by having sufficient hours of sleep every night; b) sleep in lateral positions; c) avoid sedatives and alcohol consumption 4 hours before sleep; and d) lose weight by exercise and diet where appropriate [19].

\section{Group 2 (CPAP)}

In addition to the usual advice as given to group 1, patients who had agreed to commence CPAP treatment after completing an overnight autoCPAP titration were subsequently prescribed CPAP device with a time counter recording machine run time. The CPAP pressure for each patient was set at the minimum pressure needed to abolish snoring, obstructive respiratory events, and airflow limitation for $95 \%$ of the night as determined by the overnight AutoSet CPAP titration study $[15,16]$.

\section{Carotid artery IMT}

Was measured at baseline, 6 months, and 12 months for patients in both groups. The patients were followed up at the Respiratory clinic at 1, 3, 6 and 12, months whereas objective CPAP usage was measured from the time counter for group 2.

Carotid artery IMT was assessed by B-mode ultrasound scanning with an $11-\mathrm{MHz}$ linear phase array transducer (Sonos 5500, Hewlett-Packard, Andover, Massachusetts, USA). Bilateral IMT measurements were obtained at the distal $10 \mathrm{~mm}$ of common carotid artery as described by our group previously [20,21]. The IMT was defined as the distance between the leading edge of the luminal echo to that of the media/adventitia echo and analyzed with a computerized edge-detection system (Q-Lab5.0, Xcelera, Phillips, USA). Three end- 
diastolic frames were selected, digitized, and analyzed for the mean IMT, and the average reading from these 3 frames was calculated for both right and left carotid arteries. The sole carotid scan operator (QS) was blinded to the clinical treatment status of the studied subjects and was not involved in the clinical assessment [20,21].

Blood pressure (BP) was measured in the right arm after at least 5 minutes of rest using a standard sphygmomanometer and the Korotkoff sound $\mathrm{V}$ was used as the indicator for the diastolic BP at baseline before PSG and at clinic visits at 6 months and 12 months.

\section{Statistical analysis}

The sample size was estimated by the Power Analysis and Sample Size for Windows software (PASS 2000, NCSS, Kaysville, Utah). Based on the findings of Drager et al [12], group sample sizes of 28 would achieve $80 \%$ power to detect a difference of carotid IMT between the treatment and control groups $(645+/-95$ versus 740 $+/-150$ [micron]) at a significance level (alpha) of 0.05 , using a two-sided paired Student's t test.

The primary end-point was the change in carotid artery IMT. For comparisons between the 2 groups at each time point, unpaired t-test was used for normally distributed variables and Mann-Whitney U test for non-normally distributed variables. To compare the measurements before and after CPAP treatment, paired t-test was used for normally distributed variables and Wilcoxon's signed rank test for non-normally distributed variables. Two-factor ANOVA (group versus time) with repeated measures on the factor time (baseline minus treatment) was used to test for the effect of CPAP versus CT. Data are expressed as mean $\pm \mathrm{SE}$ unless stated otherwise. A p-value of $<0.05$ is considered significant.

\section{Results}

We invited 100 patients with newly confirmed OSAS who had met the study criteria to participate in the serial carotid IMT study after completing PSG and an overnight autoCPAP titration. However, 50 eligible patients either refused to participate $(n=20)$ or could not take time off $(n=30)$ for completion of the serial carotid IMT study (Figure 1). There were no significant differences in demographics between patients who completed the carotid IMT study versus those who did not (Table 1). Among the remaining 50 patients who had completed the carotid IMT study, 22 received CT whereas 28 received CPAP treatment. The demographics and severity of OSA between the two groups were similar (Table 2). The subjects did not alter the dosage of their medications during the study.

\section{Comparisons of changes of parameters between CPAP group and CT group}

The objective CPAP usage were 4.6(0.3) and 4.7(0.4) hrs/night for the CPAP group over 6 months and 1 year respectively. The serial mean carotid artery IMT at baseline, 6 months and 12 months were 757.5(30), 720.9(20) and 704.5(20)micron for the CPAP group (Figure 2) whereas the serial IMT data for the CT group were $760.0(30), 769.8(30)$, and 777.7(30)micron respectively, $\mathrm{p}$ $=0.002$ (ANOVA for repeated measures) (Table 3 and Figure 2).

The changes in mean carotid artery IMT between baseline and 6 months were -36.6 (10) versus 9.8(10) micron for the CPAP and CT group respectively, 95\%CI ( $-77,-15.8$ micron), $\mathrm{p}=0.004$. The changes in mean carotid artery IMT between baseline and 12 months were $-53(20)$ versus $17.7(10)$ micron for the CPAP and the CT group respectively, 95\%CI (-114.8, -26.7 micron), $\mathrm{p}=0.002$. The changes in mean carotid artery IMT between 6 months and 12 months were -16.4(10) versus $8(10)$ micron for the CPAP and the CT group respectively, 95\%CI (-56, 72.2 micron), $\mathrm{p}=0.127$.

There was no correlation between objective CPAP usage and changes in carotid IMT at 6 months, $\mathrm{r}=$ $-0.185(\mathrm{p}=0.375)$ and at 12 months, $\mathrm{r}=-0.018(\mathrm{p}=$ $0.930)$.

\section{Comparisons of changes of parameters between CPAP group and CT group among those free of existing cardiovascular disease (excluding smoking and alcohol intake)}

Among those free of existing cardiovascular disease ( $\mathrm{n}=$ 24), there were no significant differences in baseline demographics and severity of OSAS between the two groups including the absence of carotid plaques (Table $4)$. The mean carotid artery IMT at baseline, 6 months and 12 months were 721.7(40), 690.8(40), and 659.2(30) micron for the CPAP group $(\mathrm{n}=12)$ with objective CPAP usage $4.5(0.7)$ and $4.7(0.7) \mathrm{hrs} /$ night over 6 months and 12 months (Figure 3 ) whereas the corresponding carotid IMT data for the CT group $(\mathrm{n}=12)$ were 660.0(20), 684.6(10) and 690.0(20) micron respectively, $\mathrm{p}=0.006$ (ANOVA for repeated measures) (Table 5 and Figure 3).

The changes in mean carotid artery IMT between baseline and 6 months were -30.8 (10) versus 24.6(10) micron for the CPAP and CT group respectively, 95\% CI $(-89.4,-21.4$ micron $), \mathrm{p}=0.003$. The changes in mean carotid artery IMT between baseline and 12 months were $-62.5(20)$ versus 30(20) micron for the CPAP and CT group respectively, 95\%CI ( $-155.4,-29.6$ micron), $\mathrm{p}$ $=0.006$. The changes in mean carotid artery IMT between 6 months and 12 months were $-31.7(20)$ versus 


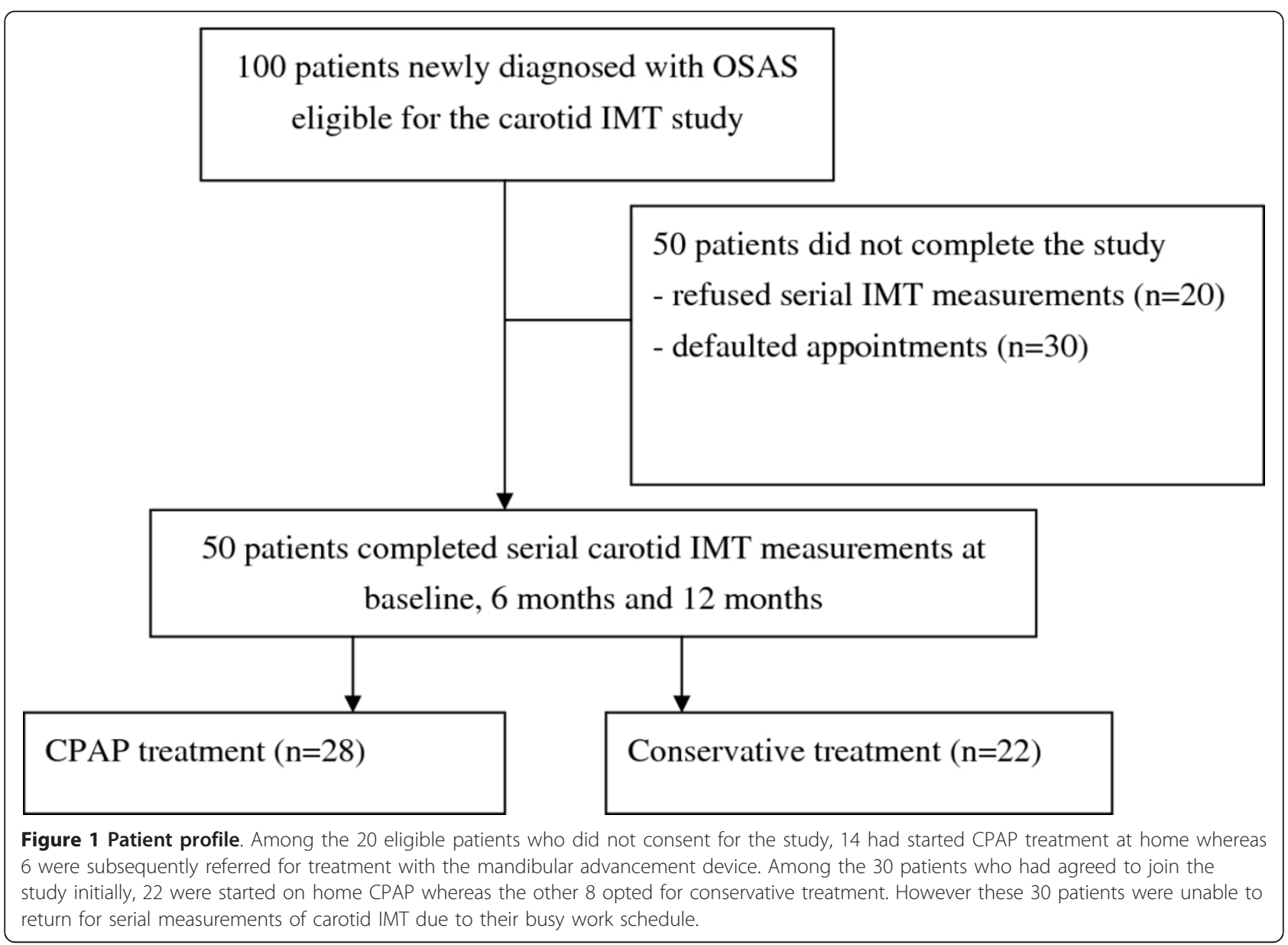

5.4(10) micron for the CPAP and the CT group respectively, 95\% CI (-87.9, 13.7 micron), $\mathrm{p}=0.144$.

\section{Discussion}

In a group of 50 symptomatic patients newly diagnosed with severe OSAS, this prospective observational study has shown that CPAP treatment $(n=28)$ resulted in significant reduction in carotid artery IMT compared to those who had opted for conservative treatment (CT, n = 22) over a study period of 12 months. Most of the reduction in carotid artery IMT when comparing CPAP against CT group appeared to have occurred within the first 6 months of treatment whereas there was no significant change from 6 to 12 months while the patients had maintained reasonable CPAP usage objectively throughout the study. Similar observations were noted in patients with and without existing cardiovascular diseases.

Data from the Sleep Heart Health Study (SHHS) have shown that modest to severe levels of OSA are associated with an approximately threefold increased risk of ischemic stroke in community-dwelling men [22]. The Wisconsin Sleep Cohort Study has provided prospective evidence that OSA is related to significantly increased odds of suffering a stroke over the next 4 years after adjustment for age and gender [23]. In an observational sleep clinic study, Yaggi et al [24] have shown that OSA significantly increases the risk of stroke or death from any cause and the increase is independent of other known risk factors. Patients with stroke and OSA have an increased risk of early death over 10 years [25], whereas sleep apnea is significantly associated with increased risk of stroke among patients with coronary artery disease over a follow-up period of 10 years [26].

There are several proposed mechanisms linking OSA and stroke. Snoring-induced vibrational injury may lead to carotid atherosclerosis [27]. There is a strong association between OSA and AF [28]. Platelet activation [16] and silent brain infarction were also more common in patients with moderate to severe OSA than in controls [29]. OSA may accelerate atherosclerosis through the effect of hypertension and other mechanisms such as insulin resistance, diabetes, and dyslipidemia. In addition, OSA can induce direct proatherogenic effects through the mechanisms of systemic inflammation, oxidative stress, vascular smooth cell activation, increased 
Table 1 Comparisons of baseline parameters between patients who completed the 12-month carotid IMT study and those who did not

\begin{tabular}{|c|c|c|c|}
\hline & Completed study $(n=50)$ & Did not complete study $(n=50)$ & $P$ value \\
\hline Male/Female & $41 / 9$ & $43 / 7$ & 0.786 \\
\hline Age (yrs) & $49.5(1.4)$ & $47.8(1.7)$ & 0.417 \\
\hline Body mass index $\left(\mathrm{kg} / \mathrm{m}^{2}\right)$ & $28.1(0.6)$ & $28.2(0.7)$ & 0.954 \\
\hline Neck circumference $(\mathrm{cm})$ & $39.6(0.5)$ & $39.4(0.5)$ & 0.703 \\
\hline Systolic blood pressure $(\mathrm{mmHg})$ & $140.3(3.1)$ & $136.5(3.1)$ & 0.384 \\
\hline Diastolic blood pressure $(\mathrm{mmHg})$ & $80.6(1.8)$ & $79.8(1.9)$ & 0.749 \\
\hline Waist circumference $(\mathrm{cm})$ & $96.8(1.6)$ & $98.0(1.7)$ & 0.611 \\
\hline Hip circumference $(\mathrm{cm})$ & $101.6(1.3)$ & $102.6(1.4)$ & 0.602 \\
\hline \multicolumn{4}{|l|}{ Smoking status } \\
\hline Non smoker & 33 & 36 & 0.666 \\
\hline Smoker & 17 & 14 & \\
\hline \multicolumn{4}{|l|}{ Alcoholic consumption } \\
\hline Non drinker & 23 & 21 & 0.840 \\
\hline Drinker & 27 & 29 & \\
\hline ESS (0-24) & $13.1(0.7)$ & $12.7(0.6)$ & 0.663 \\
\hline \multicolumn{4}{|l|}{ Congestive Heart Failure } \\
\hline Yes & 3 & 0 & 0.242 \\
\hline No & 47 & 50 & \\
\hline \multicolumn{4}{|l|}{ Diabetes } \\
\hline Yes & 6 & 8 & 0.774 \\
\hline No & 44 & 42 & \\
\hline \multicolumn{4}{|l|}{ Hypertension } \\
\hline Yes & 23 & 18 & 0.416 \\
\hline No & 27 & 32 & \\
\hline \multicolumn{4}{|l|}{ Carotid plaque in baseline study } \\
\hline Yes & 12 & 10 & 0.810 \\
\hline No & 38 & 40 & \\
\hline$\overline{\mathrm{AHI}}$ (events per hr) & $37.7(3.0)$ & $38.5(3.4)$ & 0.854 \\
\hline REM-AHI (events per hr) & $35.9(4.3)$ & $33.1(4.3)$ & 0.652 \\
\hline Non-REM-AHI (events per hr) & $37.8(3.1)$ & $38.6(3.5)$ & 0.878 \\
\hline Minimum SaO2 (\%) & $74.7(2.2)$ & $76.7(2.2)$ & 0.530 \\
\hline Mean SaO2 (\%) & $93.0(0.6)$ & $93.0(0.6)$ & 0.980 \\
\hline Arousal index (per hr of sleep) & $29.3(2.0)$ & $28.8(2.2)$ & 0.857 \\
\hline Percentage of sleep time with $\mathrm{SaO} 2<90 \%$ & $13.7(3.1)$ & $7.5(1.6)$ & 0.081 \\
\hline Snoring/TST (\%) & $14.2(3.9)$ & $23.7(4.0)$ & 0.102 \\
\hline Sleep efficiency (\%) & $83.4(1.5)$ & $79.9(1.8)$ & 0.141 \\
\hline Mean Carotid IMT (micron) & $758.6(20)$ & $742.6(20)$ & 0.573 \\
\hline
\end{tabular}

Data expressed as mean (SE). TST = total sleep time

adhesion molecule expression, monocyte/lymphocyte activation, increased lipid loading in macrophages, lipid peroxidation, and endothelial dysfunction [30].

In recent years, carotid artery IMT has been well accepted as a non-invasive tool which may predict the likelihood of acute coronary events and stroke in asymptomatic healthy subjects $[8,9]$. Carotid artery IMT has been applied by several research groups to study different OSA populations. Although cross-sectional analysis of the SHHS has found no evidence that mild to moderate SDB is associated with subclinical atherosclerosis [31], data from other groups have suggested that OSA may lead to early atherosclerosis, as reflected by increase in carotid artery IMT and occurrence of plaques, in the absence of any significant comorbidity [32-34]. In one series of OSA patients, severity of 
Table 2 Comparison of baseline parameters between patients on CPAP and Conservative treatment (CT)

\begin{tabular}{|c|c|c|c|}
\hline & $\begin{array}{c}\text { CPAP }(n= \\
28)\end{array}$ & $\begin{array}{c}\mathrm{CT}(\mathrm{n}= \\
22)\end{array}$ & $\begin{array}{c}P \\
\text { value }\end{array}$ \\
\hline Male/Female & $25 / 3$ & $16 / 6$ & 0.157 \\
\hline Age (yrs) & $48.8(1.8)$ & $50.5(2.0)$ & 0.526 \\
\hline Body mass index $\left(\mathrm{kg} / \mathrm{m}^{2}\right)$ & $28.2(0.7)$ & $28.0(1.2)$ & 0.875 \\
\hline Neck circumference $(\mathrm{cm})$ & $40.5(0.7)$ & $38.5(0.8)$ & 0.060 \\
\hline Waist circumference $(\mathrm{cm})$ & $97.9(1.9)$ & $95.3(2.8)$ & 0.437 \\
\hline Hip circumference $(\mathrm{cm})$ & $102.2(1.4)$ & $100.8(2.3)$ & 0.589 \\
\hline Cholesterol (mmol/l) & $5.8(0.4)$ & $5.2(0.2)$ & 0.180 \\
\hline HDL Cholesterol $(\mathrm{mmol} / \mathrm{l})$ & $1.3(0.1)$ & $1.3(0.1)$ & 0.923 \\
\hline LDL Cholesterol (mmol/l) & $3.3(0.3)$ & $3.0(0.2)$ & 0.449 \\
\hline Triglycerides (mmol/l) & $3.3(1.6)$ & $2.2(0.5)$ & 0.477 \\
\hline Fasting plasma glucose $(\mathrm{mmol} / \mathrm{l})$ & $5.2(0.2)$ & $5.5(0.2)$ & 0.223 \\
\hline \multicolumn{4}{|l|}{ Smoking status } \\
\hline Non smoker & 20 & 13 & 0.386 \\
\hline Smoker & 8 & 9 & \\
\hline \multicolumn{4}{|l|}{ Alcoholic consumption } \\
\hline Non drinker & 14 & 9 & 0.577 \\
\hline Drinker & 14 & 13 & \\
\hline ESS (0-24) & $13.4(0.9)$ & $12.7(1.0)$ & 0.603 \\
\hline
\end{tabular}

Congestive Heart Failure

\begin{tabular}{cccc} 
Yes & 0 & 3 & 0.079 \\
No & 28 & 19 & \\
\hline $\begin{array}{cccc}\text { Diabetes Mellitus } \\
\text { Yes }\end{array}$ & 3 & 3 & 1.000 \\
No & 25 & 19 & \\
\hline Hypertension & & & \\
Yes & 14 & 9 & 0.577 \\
No & 14 & 13 & \\
\hline
\end{tabular}

\begin{tabular}{lccc}
\hline On anti-hypertensive drugs & & & \\
Yes & 14 & 8 & 0.166 \\
No & 14 & 14 & \\
\hline
\end{tabular}

\begin{tabular}{lccc}
\hline On diabetic drugs & & & \\
Yes & 2 & 1 & 1.000 \\
\hline No & 26 & 21 &
\end{tabular}

Carotid plaque in baseline study

\begin{tabular}{lccc} 
Yes & 7 & 5 & 1.000 \\
No & 21 & 17 & \\
\hline Systolic blood pressure $(\mathrm{mmHg})$ & $140.8(3.2)$ & $139.7(6.1)$ & 0.873 \\
\hline Diastolic blood pressure $(\mathrm{mmHg})$ & $81.7(2.1)$ & $79.1(3.4)$ & 0.497 \\
\hline AHI (events per hr) & $39.0(3.6)$ & $36.1(5.1)$ & 0.633 \\
\hline REM-AHI (events per hr) & $39.1(6.5)$ & $32.5(5.7)$ & 0.459 \\
\hline Non-REM-AHI (events per hr) & $39.0(3.7)$ & $36.2(5.3)$ & 0.662 \\
\hline Minimum SaO2 (\%) & $74.7(2.1)$ & $74.8(4.2)$ & 0.983 \\
\hline Mean SaO2 (\%) & $93.7(0.4)$ & $92.1(1.2)$ & 0.209 \\
\hline Arousal index (per hr of sleep) & $31.1(2.4)$ & $27.1(3.4)$ & 0.331 \\
\hline Percentage of sleep time with & $11.1(2.7)$ & $17.0(6.3)$ & 0.399 \\
SaO2<90\% & & & \\
\hline Snoring/TST (\%) & $11.8(4.6)$ & $18.5(7.7)$ & 0.435 \\
\hline
\end{tabular}

Table 2 Comparison of baseline parameters between patients on CPAP and Conservative treatment (CT) (Continued)

\begin{tabular}{llll}
\hline Sleep efficiency (\%) & $82.5(2.0)$ & $84.5(2.3)$ & 0.513 \\
\hline Mean carotid IMT (micron) & $757.5(30)$ & $760.0(30)$ & 0.952 \\
\hline
\end{tabular}

Data expressed as mean (SE)

oxygen desaturation and BP status were the best predictors for carotid wall hypertrophy whereas plaque occurrence without known cardiovascular disease was also related to the amount of oxygen desaturation regardless of their BP status [33]. OSA-related hypoxia and systemic inflammation might be associated with progression of atherosclerosis and increased risk of cardiovascular morbidity [34]. Another study has demonstrated a relationship between lipid peroxidation, carotid artery IMT, and intermittent hypoxia in nonobese OSA patients [35] whereas in patients with minimally symptomatic OSA, diverse properties of endothelial function are impaired and arterial stiffness is increased [36]. To date, only one RCT with a small sample size has shown that CPAP therapy $(n=12)$ over 4 months could reduce carotid IMT in patients with severe OSAS free of existing cardiovascular diseases versus controls $(\mathrm{n}=12)$ (mean changes of -62 vs 8 micron for the two groups respectively, $\mathrm{p}=0.02$ ) [12].

In this study, there were significant differences when comparing the changes in carotid IMT at 6 months [-36.6 (10) versus 9.8(10)micron] and at 12 months [-53 (20) versus 17.7(10) micron] respectively from baseline between CPAP and CT groups. The magnitude of reduction in carotid IMT with CPAP was similar to those patients with OSAS with and without existing cardiovascular disease who received CPAP treatment. A clinical trial comparing rosuvastatin vs placebo among 984 low risk subjects showed no significant difference in the rate of mean maximum carotid IMT progression after 6 months (2.3 vs 10.6 micron/year, $\mathrm{p}=0.34$ ). However, carotid IMT progression rates were significantly different when comparing rosuvastatin vs placebo at 12 months, (3.2 vs 13.3 micron/year, $\mathrm{p}=0.049$ ) whereas the divergence grew with further follow-up (-0.9 vs 13.1 micron/year at 18 months and -1.4 vs 13.1 micron/year after 24 months of treatment, $\mathrm{p}<0.001$ for both time points) [37].

Although we did not find any significant correlation between objective CPAP usage and carotid IMT in this study, variability in the individual response may be related to the severity of OSA (AHI, hypoxemia) and CPAP compliance. Although the changes in carotid IMT with CPAP $(n=43)$ versus sham CPAP $(n=43)$ were not significant in the whole study population by Sharma et al [13], a subgroup analysis among those ( $\mathrm{n}=$ 


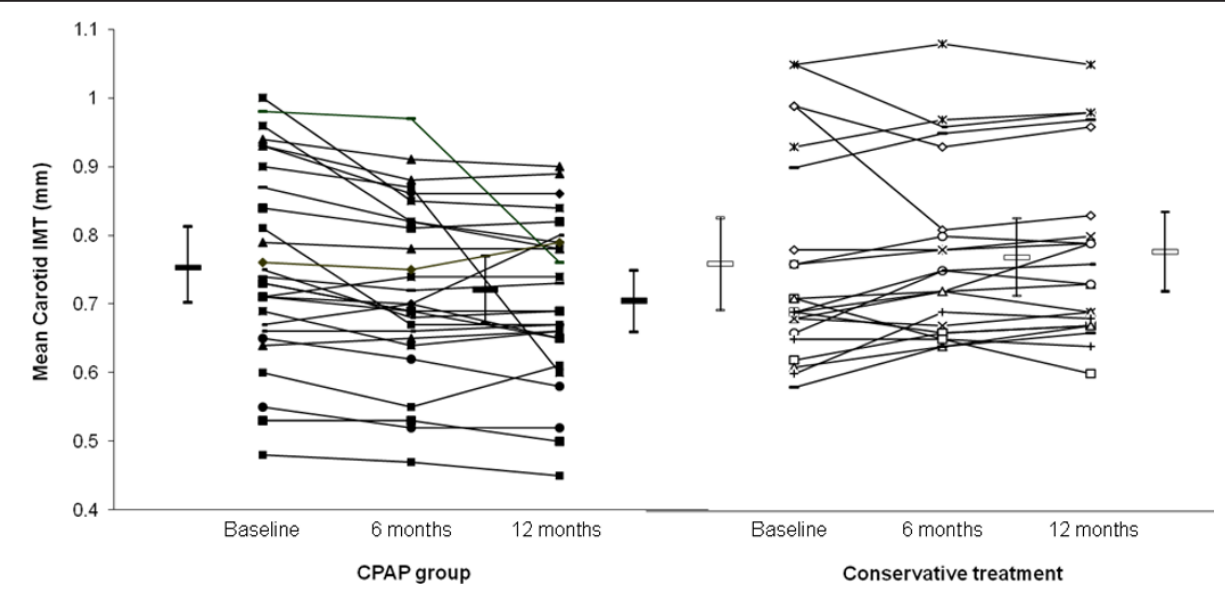

Figure 2 Shows the data plots of OSA patients on CPAP $(\mathbf{n}=28)$ and those on conservative treatment $(\mathbf{n}=22)$. The serial mean carotid artery IMT at baseline, 6 months and 12 months were 757.5(30), 720.9(20) and 704.5(20)micron for the CPAP group versus 760.0(30), 769.8(30), and 777.7(30)micron respectively for those on conservative treatment, $p=0.002$ (ANOVA for repeated measures).

51) with CPAP usage at least 5 hrs/night showed significant reduction in carotid IMT (34 vs 14 micron, $\mathrm{p}<$ 0.05) when comparing CPAP vs sham CPAP treatment over 3 months.

This study is limited by the fact that it was not a RCT as it would not be ethical to withhold CPAP treatment for symptomatic patients with severe OSAS for a 1-year study in our locality. Only $50 \%$ of eligible OSA patients had participated in this study although the demographics and severity of OSA between those who participated in this study were similar to those who did not. Likewise patients who received CPAP and those who opted for CT were similar in terms of demographics and baseline severity of OSA. Lastly only baseline data of glucose, lipids and carotid plaques were available and we did not have serial data to assess the treatment effects.

\section{Conclusion}

In summary, this prospective observational study has shown that CPAP treatment resulted in significant reduction in carotid artery IMT whereas no significant change was noted among those who opted for conservative treatment over a study period of 1 year. Reduction in carotid artery IMT within the CPAP group occurred mostly within the first 6 months of treatment in patients with and without existing cardiovascular diseases and the reduction well maintained at 12 months in patients with reasonable CPAP compliance. Patients newly diagnosed with OSAS should be

Table 3 Repeated measures comparisons of serial parameters between CPAP and CT at baseline, 6 months and 12 months

\begin{tabular}{|c|c|c|c|c|c|c|c|}
\hline & \multicolumn{3}{|c|}{ CPAP $(n=28)$} & \multicolumn{3}{|c|}{ CT $(n=22)$} & \multirow[t]{2}{*}{ P-value } \\
\hline & Baseline & $6 \mathrm{~m}$ & $12 \mathrm{~m}$ & Baseline & $6 \mathrm{~m}$ & $12 \mathrm{~m}$ & \\
\hline Neck circumference $(\mathrm{cm})$ & $40.5(0.7)$ & $40.2(0.6)$ & $40.2(0.7)$ & $38.5(0.8)$ & $38.2(0.8)$ & $38.5(0.8)$ & 0.819 \\
\hline Waist circumference $(\mathrm{cm})$ & $97.9(1.9)$ & $98.0(1.6)$ & $97.9(1.7)$ & $95.3(2.8)$ & $93.2(2.9)$ & $94.7(2.9)$ & 0.260 \\
\hline Hip circumference $(\mathrm{cm})$ & $102.2(1.4)$ & $104.0(1.5)$ & $105.2(1.3)$ & $100.8(2.3)$ & $102.5(2.2)$ & $102.7(2.1)$ & 0.653 \\
\hline Body mass index $\left(\mathrm{kg} / \mathrm{m}^{2}\right)$ & $28.2(0.7)$ & $28.6(0.7)$ & $28.3(0.8)$ & $28.0(1.2)$ & $27.7(1.1)$ & $27.9(1.2)$ & 0.042 \\
\hline Systolic BP (mmHg) & $140.8(3.2)$ & $129.0(3.6)$ & $130.7(3.6)$ & $138.4(5.4)$ & $135.9(5.4)$ & $136.1(5.2)$ & 0.593 \\
\hline Diastolic BP (mmHg) & $81.7(2.1)$ & $82.3(2.1)$ & $83.3(2.1)$ & $78.6(3.0)$ & $84.9(2.9)$ & $83.8(3.7)$ & 0.412 \\
\hline ESS (0-24) & $13.4(0.9)$ & $8.4(0.8)$ & $8.2(1.0)$ & $12.7(1.0)$ & $10.2(1.2)$ & $10.3(1.5)$ & 0.110 \\
\hline CPAP usage (hrs/night) & N/A & $4.6(0.3)$ & $4.7(0.4)$ & N/A & N/A & N/A & N/A \\
\hline Mean carotid IMT (micron) & $757.5(30)$ & $720.9(20)$ & $704.5(20)$ & $760.0(30)$ & $769.8(30)$ & $777.7(30)$ & 0.002 \\
\hline
\end{tabular}

Values are expressed as mean (SE)

The $p$-values of BP trends from baseline to 12 months within the CPAP group are as follows: systolic BP, $p=0.013 ;$ diastolic BP, $p=0.573$ 
Table 4 Comparisons of baseline parameters of patients free of any cardiovascular co-morbidity (excluding smoking and alcohol consumption) who completed serial carotid IMT measurements between CPAP and CT group

\begin{tabular}{|c|c|c|c|}
\hline & CPAP $(n=12)$ & $C T(n=12)$ & $P$ value \\
\hline Male/Female & $11 / 1$ & $9 / 3$ & 0.590 \\
\hline Age (yrs) & $44.3(2.1)$ & $48.5(1.7)$ & 0.135 \\
\hline Body mass index $\left(\mathrm{kg} / \mathrm{m}^{2}\right)$ & $27.4(1.1)$ & $25.9(1.1)$ & 0.357 \\
\hline Neck circumference $(\mathrm{cm})$ & $40.0(1.1)$ & $37.6(1.0)$ & 0.127 \\
\hline Waist circumference $(\mathrm{cm})$ & $96.3(3.2)$ & $91.9(2.9)$ & 0.320 \\
\hline Hip circumference $(\mathrm{cm})$ & $101.7(2.2)$ & $97.5(2.1)$ & 0.179 \\
\hline Systolic blood pressure $(\mathrm{mmHg})$ & $139.9(3.6)$ & $129.7(6.5)$ & 0.164 \\
\hline Diastolic blood pressure $(\mathrm{mmHg})$ & $81.7(2.7)$ & $75.7(3.2)$ & 0.160 \\
\hline Cholesterol (mmol/l) & $5.8(0.5)$ & $5.4(0.4)$ & 0.535 \\
\hline HDL Cholesterol (mmol/l) & $1.5(0.3)$ & $1.2(0.1)$ & 0.331 \\
\hline LDL Cholesterol (mmol/l) & $3.7(0.4)$ & $3.4(0.3)$ & 0.548 \\
\hline Triglycerides $(\mathrm{mmol} / \mathrm{l})$ & $1.3(0.3)$ & $1.8(0.3)$ & 0.338 \\
\hline Fasting plasma glucose $(\mathrm{mmol} / \mathrm{l})$ & $5.2(0.3)$ & $5.1(0.1)$ & 0.676 \\
\hline ESS $(0-24)$ & $12.7(1.0)$ & $11.5(1.3)$ & 0.477 \\
\hline \multicolumn{4}{|l|}{ Smoking status } \\
\hline Non smoker & 10 & 8 & 0.640 \\
\hline Smoker & 2 & 4 & \\
\hline \multicolumn{4}{|l|}{ Alcoholic consumption } \\
\hline Non drinker & 7 & 5 & 0.684 \\
\hline Drinker & 5 & 7 & \\
\hline $\mathrm{AHI}$ (events per hr) & $36.3(6.5)$ & $35.5(6.6)$ & 0.929 \\
\hline REM-AHI (events per hr) & $34.4(6.5)$ & $30.5(7.6)$ & 0.712 \\
\hline Non-REM-AHI (events per hr) & $36.4(6.8)$ & $35.7(6.7)$ & 0.942 \\
\hline Minimum SaO2 (\%) & $77.0(3.4)$ & $80.0(2.9)$ & 0.509 \\
\hline Mean $\mathrm{SaO} 2(\%)$ & $94.2(0.7)$ & $93.9(0.9)$ & 0.827 \\
\hline Arousal index (per hr of sleep) & $29.1(4.8)$ & $26.8(5.1)$ & 0.746 \\
\hline Percentage of sleep time with $\mathrm{SaO} 2<90 \%(\%)$ & $10.3(4.7)$ & $7.6(3.2)$ & 0.645 \\
\hline Snoring/TST (\%) & $16.2(7.7)$ & $7.0(3.2)$ & 0.510 \\
\hline Sleep efficiency (\%) & $81.9(3.0)$ & $81.6(3.7)$ & 0.943 \\
\hline Mean carotid IMT (micron) & $721.7(40)$ & $660.0(20)$ & 0.153 \\
\hline
\end{tabular}

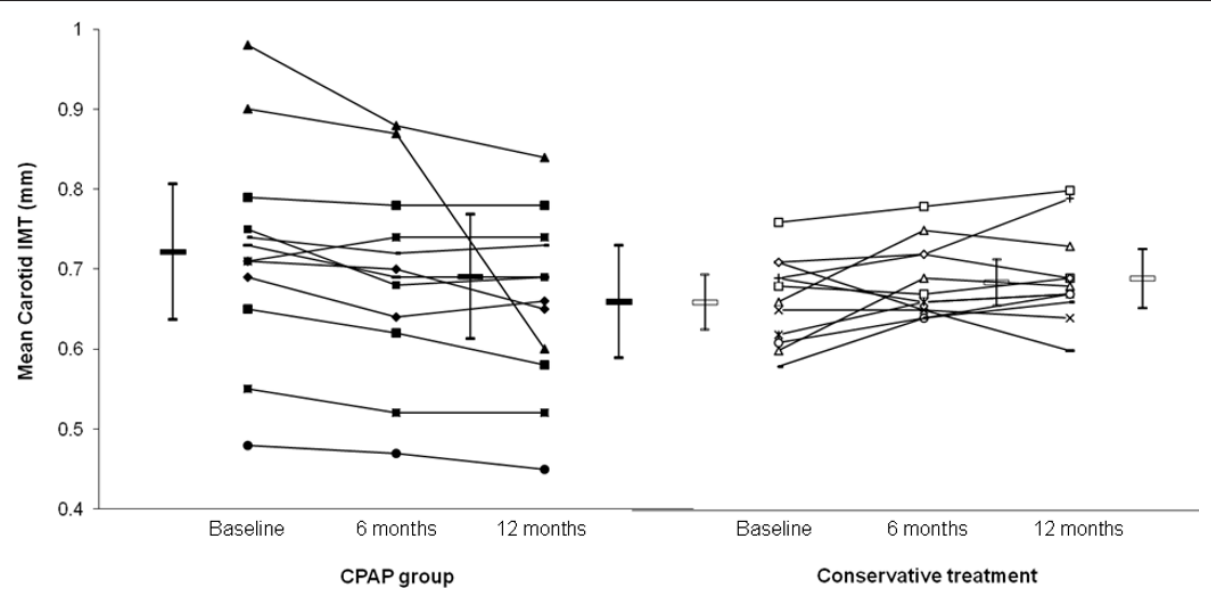

Figure 3 Shows the data plots of OSA patients free of existing cardiovascular diseases (excluding smoking and alcohol consumption). The mean carotid artery IMT at baseline, 6 months and 12 months were 721.7(40), 690.8(40) and 659.2(30) micron for the CPAP group $(n=12)$ versus 660.0(20), 684.6(10) and 690.0(20)micron respectively for those on conservative treatment ( $n=12), p=0.006$ (ANOVA for repeated measures). 
Table 5 Repeated Measures - Comparisons of serial parameters between CPAP and CT at baseline, 6 months and 12 months

\begin{tabular}{|c|c|c|c|c|c|c|c|}
\hline & \multicolumn{3}{|c|}{ CPAP $(n=12)$} & \multicolumn{3}{|c|}{$C T(n=12)$} & \multirow[t]{2}{*}{ P-value } \\
\hline & Baseline & $6 \mathrm{~m}$ & $12 \mathrm{~m}$ & Baseline & $6 \mathrm{~m}$ & $12 \mathrm{~m}$ & \\
\hline Neck circumference $(\mathrm{cm})$ & $40.0(1.1)$ & $39.2(0.9)$ & $39.4(1.0)$ & $37.6(1.0)$ & $37.4(1.0)$ & $37.5(1.1)$ & 0.516 \\
\hline Waist circumference $(\mathrm{cm})$ & $96.3(3.2)$ & $94.3(3.3)$ & $94.6(3.5)$ & $91.9(2.9)$ & 88.7 (3.6) & $91.1(3.5)$ & 0.527 \\
\hline Hip circumference $(\mathrm{cm})$ & $101.7(2.2)$ & $102.6(2.5)$ & $104.2(2.3)$ & $97.5(2.1)$ & $98.8(2.3)$ & $100.4(2.6)$ & 0.967 \\
\hline Body mass index $\left(\mathrm{kg} / \mathrm{m}^{2}\right)$ & $27.4(1.1)$ & $27.6(1.1)$ & $27.4(1.1)$ & $25.9(1.1)$ & $25.9(1.1)$ & $26.0(1.2)$ & 0.723 \\
\hline Systolic BP (mmHg) & $139.9(3.6)$ & $118.0(5.0)$ & $121.7(4.7)$ & $128.9(5.7)$ & $124.8(4.7)$ & $126.8(6.8)$ & 0.108 \\
\hline Diastolic BP $(\mathrm{mmHg})$ & $81.7(2.7)$ & $76.9(3.8)$ & $80.0(3.4)$ & $75.2(2.9)$ & $82.4(3.9)$ & $81.5(5.3)$ & 0.219 \\
\hline ESS (0-24) & $12.7(1.0)$ & $7.3(1.3)$ & $6.4(1.2)$ & $11.5(1.3)$ & $8.7(1.4)$ & $8.6(1.6)$ & 0.145 \\
\hline CPAP usage (hrs/night) & $\mathrm{N} / \mathrm{A}$ & $4.5(0.7)$ & $4.7(0.7)$ & N/A & N/A & $\mathrm{N} / \mathrm{A}$ & N/A \\
\hline Mean carotid IMT (micron) & $721.7(40)$ & $690.8(40)$ & $659.2(30)$ & $660.0(20)$ & $684.6(10)$ & $690.0(20)$ & 0.006 \\
\hline
\end{tabular}

Values are expressed as mean (SE)

The $p$-values of BP trends from baseline to 12 months within the CPAP group are as follows: systolic BP, $p<0.001 ;$ diastolic BP, $p=0.517$

encouraged to comply with CPAP not just to relieve daytime sleepiness but there may be cardio-protective effects. Further studies with the RCT design over short to medium term are warranted to assess the effect of CPAP on carotid IMT.

\section{Abbreviations}

AF: Atrial fibrillation; AHI: Apnea-hypopnea index; CPAP: Continuous positive airway pressure; $C T$ : Conservative treatment; ESS: Epworth sleepiness score; IMT: Intima-media thickness; OSAS: Obstructive sleep apnea syndrome; PSG: Polysomnography; TST: Total sleep time.

\section{Acknowledgements}

This study was funded by the CUHK Direct Grant \#2041204.

\section{Authors' contributions}

DSH was the guarantor responsible for the study conception and design, data interpretation and writing of the manuscript. QS was responsible for the carotid IMT measurement. CCS and CMY were responsible for interpretation of the carotid IMT data and critical revision of the manuscript. FWK, JN, SSN, AHT, TOC and KWT were responsible for interpretation of sleep study and clinical assessment of patients. All authors have read and approved the submitted manuscript.

\section{Competing interests}

The authors declare that they have no competing interests.

Received: 30 December 2011 Accepted: 16 March 2012 Published: 16 March 2012

\section{References}

1. Engleman HM, Douglas NJ: Sleepiness, cognitive function, and quality of life in obstructive sleep apnoea/hypopnoea syndrome. Thorax 2004 59:618-622.

2. Marin JM, Carrizo SJ, Vicente E, Agusti AG: Long-term cardiovascular outcomes in men with obstructive sleep apnoea-hypopnoea with or without treatment with continuous positive airway pressure: an observational study. Lancet 2005, 365:1046-1053.

3. Buchner NJ, Sanner BM, Borgel J, Rump LC: Continuous positive airway pressure treatment of mild to moderate obstructive sleep apnea reduces cardiovascular risk. Am J Respir Crit Care Med 2007, 176:1274-1280.

4. Young T, Finn L, Peppard PE, Szklo-Coxe M, Austin D, Nieto FJ, Stubbs R, Hla KM: Sleep disordered breathing and mortality: eighteen-year followup of the Wisconsin sleep cohort. Sleep 2008, 31:1071-1078.
5. Marshall NS, Wong KK, Liu PY, Cullen SR, Knuiman MW, Grunstein RR: Sleep apnea as an independent risk factor for all-cause mortality: the Busselton Health Study. Sleep 2008, 31:1079-1085.

6. Punjabi NM, Caffo BS, Goodwin JL, Gottlieb DJ, Newman AB, O'Connor GT, Rapoport DM, Redline S, Resnick HE, Robbins JA, Shahar E, Unruh ML, Samet JM: Sleep-disordered breathing and mortality: a prospective cohort study. PLoS Med 2009, 6:e1000132

7. Bradley TD, Floras JS: Obstructive sleep apnea and its cardiovascular consequences. Lancet 2009, 373:82-93.

8. Bots ML, Hoes AW, Koudstaal PJ, Hofman A, Grobbee DE: Common carotid intima-media thickness and risk of stroke and myocardial infarction: the Rotterdam study. Circulation 1997, 96:1432-1437.

9. O'leary DH, Polak JF, Kronmai RA, Manolio TA, Burke GL, Wolfson SK Jr: Carotid artery intima and media thickness as a risk factor for myocardial infarction and stroke in older adults. N Engl J Med 1999, 340:14-22.

10. Suzuki T, Nakano H, Maekawa J, Okamoto Y, Ohnishi Y, Yamauchi M, Kimura H: Obstructive sleep apnea and carotid artery intima-media thickness. Sleep 2004, 27:129-133.

11. Schulz R, Seeger W, Fegbeutel C, Hüsken H, Bödeker RH, Tillmanns H, Grebe M: Changes in extracranial arteries in obstructive sleep apnoea. Eur Respir J 2005, 25:69-74.

12. Drager LF, Bortolotto LA, Figueiredo AC, Krieger EM, Lorenzi GF: Effects of continuous positive airway pressure on early signs of atherosclerosis in obstructive sleep apnea. Am J Respir Crit Care Med 2007, 176:706-712.

13. Sharma SK, Agrawal S, Damodaran D, Sreenivas V, Kadhiravan T, Lakshmy R, Jagia $P$, Kumar A: CPAP for the metabolic syndrome in patients with obstructive sleep apnea. N Engl J Med 2011, 365:2277-2286.

14. The report of an American Academy of Sleep Medicine Task Force: Sleeprelated breathing disorders in adults: recommendations for Syndrome definition and measurement techniques in clinical research. Sleep 1999, 22:667-690.

15. Hui DS, To KW, Ko FW, Fok JP, Chan MC, Ngai JC, Tung AH, Ho CW, Tong MW, Szeto CC, Yu CM: Nasal CPAP reduces systemic blood pressure in patients with Obstructive sleep apnea and mild sleepiness. Thorax 2006, 61:1083-1090.

16. Hui DS, Ko FW, Fok JP, Chan MC, Li TS, Tomlinson B, Cheng G: The effects of nasal CPAP on platelet activation in obstructive sleep apnea. Chest 2004, 125:1768-1775.

17. Rechtschaffen A, Kales A: A manual of standardized terminology, techniques and scoring system for sleep stages of human subjects Los Angeles: Brain Information Service, Brain Information Institute, University of California; 1968.

18. American Sleep Disorders Association (ASDA): EEG arousals: scoring rules and examples: a preliminary report from the Sleep Disorders Atlas Task Force of the American Sleep Disorders Association. Sleep 1992, 15:173-184.

19. Ballester E, Badia JR, Hernandez L, Carrasco E, de Pablo J, Fornas C, Rodriguez-Roisin R, Montserrat JM: Evidence of the effectiveness of 
continuous positive airway pressure in the treatment of sleep apnea/ hypopnea syndrome. Am J Respir Crit Care Med 1999, 159:495-501.

20. Woo KS, Chook P, Raitakari OT, McQuillan B, Feng JZ, Celermajer DS: Westernization of Chinese adults and increased subclinical atherosclerosis. Arterioscler Thromb Vasc Biol 1999, 19:2487-2493.

21. Woo KS, Chook P, Yu CW, Sung RY, Qiao M, Leung SS, Lam CW, Metreweli C, Celermajer DS: Effects of diet and exercise on obesityrelated vascular dysfunction in children. Circulation 2004, 109:1981-1986.

22. Redline S, Yenokyan G, Gottlieb DJ, Shahar E, O'Connor GT, Resnick HE, Diener-West M, Sanders MH, Wolf PA, Geraghty EM, Ali T, Lebowitz M, Punjabi NM: Obstructive sleep apnea-hypopnea and incident stroke: the sleep heart health study. Am J Respir Crit Care Med 2010, 182:269-277.

23. Arzt M, Young T, Finn L, Skatrud JB, Bradley TD: Association of sleepdisordered breathing and the occurrence of stroke. Am J Respir Crit Care Med 2005, 172:1447-1451.

24. Yaggi HK, Concato J, Kernan WN, Lichtman JH, Brass LM, Mohsenin V: Obstructive sleep apnea as a risk factor for stroke and death. $N$ Engl J Med 2005, 353:2034-2041.

25. Sahlin C, Sandberg O, Gustafson Y, Bucht G, Carlberg B, Stenlund H, Franklin KA: Obstructive sleep apnea is a risk factor for death in patients with stroke: a 10-year follow-up. Arch Intern Med 2008, 168:297-301.

26. Valham F, Mooe T, Rabben T, Stenlund H, Wiklund U, Franklin KA: Increased risk of stroke in patients with coronary artery disease and sleep apnea: a 10-year follow-up. Circulation 2008, 118:955-960.

27. Lee SA, Amis TC, Byth K, Kairaitis K, Robinson TD, Wheatley JR: Heavy snoring as a cause of carotid artery atherosclerosis. Sleep 2008, 31:1207-1213.

28. Gami AS, Hodge DO, Herges RM, Olson EJ, Nykodym J, Kara T, Somers VK: Obstructive sleep apnea, obesity, and the risk of incident atrial fibrillation. J Am Coll Cardiol 2007, 49:565-571.

29. Minoguchi K, Yokoe T, Tazaki T, Minoguchi H, Oda N, Tanaka A, Yamamoto M, Ohta S, O'Donnell CP, Adachi M: Silent brain infarction and platelet activation in obstructive sleep apnea. Am J Respir Crit Care Med 2007, 175:612-617.

30. Drager LF, Polotsky VY, Lorenzi-Filho G: Obstructive sleep apnea: an emerging risk factor for atherosclerosis. Chest 2011, 140:534-542.

31. Wattanaki K, Boland L, Punjabi NM, Shahar E: Relation of sleep-disordered breathing to carotid plaque and intima-media thickness. Atherosclerosis 2008, 197:125-131.

32. Drager LF, Bortolotto LA, Lorenzi MC, Figueiredo AC, Krieger EM, LorenziFilho G: Early signs of atherosclerosis in obstructive sleep apnea. Am J Respir Crit Care Med 2005, 172:613-618.

33. Baguet JP, Hammer L, Lévy P, Pierre H, Launois S, Mallion JM, Pépin JL: The severity of oxygen desaturation is predictive of carotid wall thickening and plaque occurrence. Chest 2005, 128:3407-3412.

34. Minoguchi K, Yokoe T, Tazaki T, Minoguchi H, Tanaka A, Oda N, Okada S, Ohta S, Naito H, Adachi M: Increased carotid intima-media thickness and serum inflammatory markers in obstructive sleep apnea. Am J Respir Crit Care Med 2005, 172:625-630.

35. Monneret D, Pepin JL, Godin-Ribuot D, Ducros V, Baguet JP, Levy P, Faure P: Association of urinary 15-F2t-isoprostane level with oxygen desaturation and carotid intima-media thickness in nonobese sleep apnea patients. Free Radic Biol Med 2010, 48:619-625.

36. Kohler M, Craig S, Nicoll D, Leeson P, Davies RJ, Stradling JR: Endothelial function and arterial stiffness in minimally symptomatic obstructive sleep apnea. Am J Respir Crit Care Med 2008, 178:984-988.

37. Bots ML, Palmer MK, Dogan S, Plantinga Y, Raichlen JS, Evans GW, O'Leary DH, Grobbee DE, Crouse JR 3rd, METEOR Study Group: Intensive lipid lowering may reduce progression of carotid atherosclerosis within 12 months of treatment: the METEOR study. J Intern Med 2009, 265:698-707.

doi:10.1186/1465-9921-13-22

Cite this article as: Hui et al:: A prospective cohort study of the longterm effects of CPAP on carotid artery intima-media thickness in Obstructive sleep apnea syndrome. Respiratory Research 201213.22

\section{Submit your next manuscript to BioMed Central and take full advantage of:}

- Convenient online submission

- Thorough peer review

- No space constraints or color figure charges

- Immediate publication on acceptance

- Inclusion in PubMed, CAS, Scopus and Google Scholar

- Research which is freely available for redistribution

Submit your manuscript at www.biomedcentral.com/submit 